\title{
ACCIONES DE FILIACIÓN Y ABDICACIÓN EN LA MONARQUÍA CONSTITUCIONAL BELGA
}

\author{
ADORACIÓN GALERA VICTORIA \\ Profesora Titular (A) de Derecho constitucional \\ Universidad de Granada
}

\section{SUMARIO}

I. Introducción. II. Abdicación y prerrogativas regias. III. El derecho a la igualdad entre los hijos y el respeto a la vida familiar y personal. IV. Conclusiones.

\section{INTRODUCCIÓN}

El presente trabajo analiza la decisión de la Cour constitutionnelle belga 18/2016, de 3 de febrero, que examina la adecuación del artículo 318 en sus apartados primero y segundo del Código civil, con la Constitución belga conforme al alcance de los derechos a la vida privada y familiar en marco de interpretación realizada por el TEDH del artículo 8 del CEDH. Las cuestiones prejudiciales planteadas por el tribunal de primera instancia francófono de Bruselas ante la Cour constitutionnelle ${ }^{l}$ evidencian la relevancia constitucional de una causa que sitúa en el centro de la reflexión jurídica el derecho de igualdad y no discriminación (artículo 10 y 11 Constitución belga, en adelante CB) ${ }^{2}$, por su relación con los derechos al respeto a la vida privada y familiar (artículo $22 \mathrm{CB})^{3}$ y al desarro-

1 Cuestiones prejudiciales planteadas por decisión de 27 de noviembre de 2014, del tribunal de primera instancia francófono de Bruselas asunto Delphine Boël contra Jacques Boël y S.M. el Rey Albert II de Bélgica.

2 En su redacción literal, el artículo 10 Constitución belga dispone: «Il n’y a dans l'État aucune distinction d'ordres. Les Belges sont égaux devant la loi; seuls ils sont admissibles aux emplois civils et militaires, sauf les exceptions qui peuvent être établies par une loi pour des cas particuliers. L'égalité des femmes et des hommes est garantie». Por su parte, el artículo 11 establece «La jouissance des droits et libertés reconnus aux Belges doit être assurée sans discrimination. A cette fin, la loi et le décret garantissent notamment les droits et libertés des minorités idéologiques et philosophiques».

3 Según el artículo 22 Constitución belga: «Chacun a droit au respect de sa vie privée et familiale, sauf dans les cas et conditions fixés par la loi. La loi, le décret ou la règle visée à l'article 134 garantissent la protection de ce droit». 
llo del niño y la garantía del carácter preferente del interés del hijo en todo aquello que le concierna (artículo 22 bis CB) ${ }^{4}$. Como podrá advertirse, la dialéctica jurídica se proyecta especialmente sobre la garantía de las posiciones de igualdad de los hijos y en el respeto a la vida personal y familiar constitucionalmente garantizados orientada a proteger el interés preferente y superior del hijo.

Junto a ello, y al margen de la repercusión mediática y social del origen en sede judicial de la decisión de la Oour $^{5}$, los hechos que sustancian la causa ponen en el centro de este análisis, una institución del Estado constitucional belga, la monarquía. Y es que, las acciones de filiación objeto del proceso judicial se plantean frente al rey Alberto II, monarca abdicado ${ }^{6}$. Como sucediera con ocasión del análisis del precedente existente en el sistema constitucional español ${ }^{7}$, en estas páginas retomaremos la institución de la inviolabilidad regia y el fuero jurisdiccional, prerrogativas reconocidas en el sistema parlamentario belga al monarca reinante por la Constitución en virtud de la naturaleza irresponsable de sus actos (artículos 88 y 106) ${ }^{8}$. El debate jurídico planteado en sede judicial se construye sobre una delimitación temporal de las prerrogativas regias y los inmediatos efectos que se derivan de la pérdida de estas prerrogativas. Pues, a diferencia del caso español, en el sistema constitucional belga el monarca abdicado, al no ostentar la titularidad de la jefatura del Estado queda desprovisto de toda prerrogativa. Así pues, al margen de los hechos que sustancian la reclamación de filiación, nuestra atención se centra en los elementos constitucionales y los argumentos jurídicos esgrimidos en el pronunciamiento en sede constitucional que, según se expone en este estudio, se centran en los derechos constitucionales que entran en conflicto en los juicios de filiación. En definitiva, la decisión de la Cour Costitutionnelle belga se proyecta sobre cuestiones básicas de los regímenes constitucionales actuales, que dado su interés constitucional merecen, a nuestro juicio, ser objeto de reflexión jurídica.

4 Art. 22bis (2. ${ }^{a}$ modificación) «Chaque enfant a droit au respect de son intégrité morale, physique, psychique et sexuelle. Chaque enfant a le droit de s'exprimer sur toute question qui le concerne; son opinion est prise en considération, eu égard à son âge et à son discernement. Chaque enfant a le droit de bénéficier des mesures et services qui concourent à son développement. Dans toute décision qui le concerne, l'intérêt de l'enfant est pris en considération de manière primordiale. La loi, le décret ou la règle visée à l'article 134 garantissent ces droits de l'enfant».

5 Resulta no obstante destacable que los hechos que sustancian el asunto han encontrando espacio incluso en la descripción de momentos clave del reinado de Alberto II Vid. al respecto, http://www.histoire-des-belges.be/au-fil-du-temps/epoque-contemporaine/le-regne-dalbert-ii (Consultado el 10 de junio de 2016).

6 El Acta oficial de Abdicación en el trono del Rey Alberto II de Bélgica mediante la que pondría fin a su reinado y renunciaba a sus poderes constitucionales, sería firmada el 21 de julio de 2013 a las 10.30 hs. y publicada en el Moniteur belge de esa fecha. Texto disponible en http://justice.belgium.be/fr/service_public_federal_justice/organisation/moniteur_belge (Consultado el 20/06/2016).

7 Sobre esta cuestión, permítaseme la remisión a mi trabajo «Cuestiones constitucionales sobre las acciones de filiación y la Corona», Teoría y Realidad Constitucional, n. ${ }^{\circ}$ 36, 2015, pp. 441-456.

8 Según la redacción literal del artículo $88 \mathrm{CB}$ «La personne du Roi est inviolable; ses ministres sont responsables». Por su parte, el artículo 106 CB dispone «Aucun acte du Roi ne peut avoir d'effet, s'il n'est contresigné par un ministre, qui, par cela seul, s’en rend responsable». 


\section{ABDICACIÓN Y PRERROGATIVAS REGIAS}

En Bélgica, atendiendo a la lógica de los regímenes monárquico-parlamentario europeos, la Corona ha sabido y debido adaptarse a los presupuestos del constitucionalismo democrático'. El Rey y la familia real adoptan un importante perfil simbólico y representativo de la permanencia del Estado como mecanismo de compensación a la pérdida de poderes reales ${ }^{10}$. Las funciones del monarca como institución del Estado constitucional derivan directamente de la Constitución y, dentro del marco fijado por la Constitución, las leyes podrán fijar el alcance de las facultades regias (artículo $105 \mathrm{CB})^{11}$. El texto constitucional delimita la posición del monarca en el sistema institucional belga de una forma precisa, «minimalista» incluso, que contrasta con la descripción constitucional de otras monarquías europeas $^{12}$, y lo hace a partir de la atribución constitucional de sus funciones y del carácter necesario o debido de sus actos.

En efecto, el ejercicio de las funciones del titular de la Jefatura del Estado requiere la intervención de otra institución del Estado, los/as ministros/as, quienes asumen la responsabilidad derivada de los actos regios (artículos 88 y 106 CB). La Constitución recoge así una de las clásicas prerrogativas del monarca, la inviolabilidad, vinculándola con otro tradicional instituto jurídico en las monarquías parlamentarias, el refrendo, en este caso, ministerial. Según estas normas constitucionales, el refrendo cubre todos los actos realizados por el monarca que puedan ser susceptibles de tener una repercusión política, directa o indirecta, con la destacable excepción del acto de la abdicación al trono ${ }^{13}$. Es en efecto, el único

9 Sobre esta cuestión vid. el número monógráfico titulado «Monarchies», de Poivoirs. Revue française d'ëtudes constitutionnelles et politiques, $\mathrm{n} .^{\circ}$ 78, 1996, en especial los estudios de M. Herrero DE Miñon, «Monarchie et développement démocratique» (pp. 7-22); P. Lauvaux, «Les monarchies: inventaire des types (pp. 23-42), F. Delpérée, «La fonction du roi» (pp. 43-54) y M. Duverger, «Les monarchies républicaines» (pp. 107-122). A. Stepan, J.J. LinZ, J.F. Minoves, «Monarquías democráticas parlamentarias», Documents CIBOD, n. ${ }^{\circ}$ 6, 2016. Entre la doctrina española vid. entre otros los estudios de M. García Canales, «Las Monarquías Parlamentarias Europeas», A. Torres del Moral y Y. Gómez SÁNCHEZ (coords.): Estudios sobre la Monarquía. Madrid: UNED, 1995; pp. 43-59 y «Las Monarquías Parlamentarias Europeas», A. Torres del Moral (dir.): Monarquía y Constitución. Madrid: Colex, 2001, pp. 81-94.

10 A este respecto, P. Wynants, «Trois paradoxes de la Monarchie en Belgique», La Revue Nouvelle. La Monarchie dans l'État belge, n. ${ }^{\circ} 115$ 3-4, 2002, pp. 8-23. Sobre la institución monárquica en el sistema constitucional belga, véase, entre otros, F. Delpérée y B. Dupret, «La Rois des belges», Poivoirs. Revue française d'ëtudes constitutionnelles et politiques, n. ${ }^{\circ}$ 54, 1990, pp. 15-24; P. Lauvaux, «Le roi» en el número monógráfico sobre «La Belgique», de Poivoirs. Revue française d'ëtudes constitutionnelles et politiques, n. ${ }^{\circ} 136$, 2011, pp. 71-86.

11 Conforme al artículo $105 \mathrm{CB}$ «Le Roi n'a d'autres pouvoirs que ceux que lui attribuent formellement la Constitution et les lois particulières portées en vertu de la Constitution même».

12 Según ha destacado P. Lauvaux, «Le Roi», op. cit., p. 71.

13 Aunque la intervención del correspondiente miembro del gobierno resulta sin duda conveniente, Cfr. C. Behrendt, Droit constitutionnel belge, Syllabus du cours — Année académique 2015-2016. Université de Liège. Faculté de droit, de science politique et de criminologie, 2015, pp. 192. Documento disponible en http://hdl.handle.net/2268/100234 
acto del rey que, teniendo una evidente trascendencia política, no requiere el concurso de la voluntad de un/a ministro/a para garantizar su validez.

La inviolabilidad regia significa además, que el rey no puede ser perseguido, detenido o condenado por causas penales ni, en el ámbito civil, ser citado a comparecer personalmente ante un tribunal, incluidos aquellos asuntos que recaigan sobre la administración de su patrimonio ${ }^{14}$. Se consolida así una prerrogativa con el objetivo garantizar la permanencia y el papel conciliador de la institución al situarla por encima de los grupos políticos y sociales ${ }^{15}$. La descripción del estatuto del rey es así precisada sobre la base de su función arbitral y moderadora ${ }^{16}$, desde una perspectiva objetiva y con unos efectos limitados temporal y subjetivamente a la persona que ostenta la jefatura del Estado.

$\mathrm{Y}$ es que, en efecto, en el régimen monárquico-parlamentario belga las prerrogativas se vinculan únicamente a la persona que ostenta el cargo de esta institución del Estado y se delimita temporalmente por el periodo del reinado. La descripción constitucional del estatuto personal del monarca belga incluye la facultad de transmitir los poderes constitucionalmente asignados donde se advierte, por un lado que se excluye expresamente a los hijos extramatrimoniales de los derechos hereditarios al trono (artículo $85 \mathrm{CB})^{17} \mathrm{y}$, por otro, la paradójica ausencia de regulación del supuesto de abdicación al trono ${ }^{18}$. En todo caso, con la transmisión de esos poderes regios, se trasmite también las prerrogativas.

La inviolabilidad es pues, un atributo personal del rey que no se extiende a otros miembros de la familia real y cesa en los supuestos de abdicación. Se advierte pues una diferencia cualitativa y cuantitativa en la concepción de las prerrogativas regias con respecto al sistema constitucional español, donde los miembros de la familia real y, entre ellos el rey abdicado ${ }^{19}$ mantiene un estatuto jurídico singular

14 No obstante, por razones de igualad se admiten causas contra la administración del patrimonio real, si bien no es el monarca quien comparece, sino el administrador (Intendant) de ese patrimonio. Según el artículo $89 \mathrm{CB}$, una ley determinara la denominada Liste civile, esto es, los medios económicos que se ponen anualmente a disposición del monarca para garantizar su independencia financiera durante su reinado. Al respecto, C. BEHRENDT, Droit constitutionnel belge, op. cit., 193-194.

$15 \mathrm{Al}$ respecto, vid. Chambre de représentants de Belgique, «Le statut du Chef de l'État», Service des relations publiques et internationales, publicado el 07.05.2015, Texto disponible en https://www.lachambre. be/kvvcr/pdf_sections/pri/fiche/fr_07_00.pdf (última consulta 20/05/2016).

16 Función arbitral y mediadora de la escena política que, sin embargo, en ocasiones, ha conducido a la monarquía a adoptar un papel aún muy activo motivada por tensiones entre las fuerzas políticas, según ha sido descrito por P. Lauvaux, «Le Roi», op. cit., en particular, pp. 75 y ss.

17 De acuerdo con el tenor literal del art. $85 \mathrm{CB}$ «Les pouvoirs constitutionnels du Roi sont héréditaires dans la descendance directe, naturelle et légitime de S.M. Léopold, Georges, Chrétien, Frédéric de Saxe-Cobourg, par ordre de primogeniture».

18 Sobre el contenido estas normas constitucionales, y la aplicación analógica del artículo 90 CB para el procedimiento de abdicación vid. C. BEHREndt, Droit constitutionnel belge, op. cit., pp. 194 a 197.

19 La abdicación del Rey Don Juan Carlos I de Borbón se hizo efectiva mediante la Ley Orgánica 3/2014, de 18 de junio. Sobre la naturaleza y caracteres del acto de la abdicación y, en particular, de la abdicación de D. Juan Carlos I, vid. A. Torres Del Moral, «En torno a la abdicación de la Corona», en Revista Española de Derecho Constitucional, n. ${ }^{\circ} 102,2014$, pp. 13 y ss. 
por la vía del fuero jurisdiccional no exento de dialéctica dogmática ${ }^{20}$. En cambio, las consecuencias de la abdicación para el rey Alberto II son en este punto, claras, al quedar desligado de toda prerrogativa. Para el caso estudiado en estas páginas esta diferencia conlleva consecuencias notables en la sustanciación del proceso judicial.

En suma, la regulación constitucional del estatuto del monarca como jefe del Estado belga, equilibra mejor los presupuestos y objetivos a los que sirven las prerrogativas regias en un sistema democrático con las exigencias derivadas del principio de igualdad. $Y$ es que, ante la debilidad de los argumentos que sostienen una noción absoluta o amplia de estas prerrogativas en los regímenes constitucionales actuales por su difícil encaje con los principios del Estado constitucional de Derecho, conviene limitar este instituto jurídico a los actos realizados por el monarca reinante como titular de la Jefatura del Estado. Las prerrogativas regias, por su vinculación jurídica con la institución de la Jefatura del Estado, merecen ser limitadas temporal y materialmente a los actos públicos que realiza su titular. Esta comprensión reducida o limitada permite cohonestar las funciones del titular efectivo de la Jefatura del Estado con los principios del constitucionalismo democrático y de Derecho ${ }^{21}$ y, de forma particular, con el respeto al principio de igualdad de todas las personas ante la ley y del derecho a la tutela judicial efectiva.

\section{EL DERECHO A LA IGUALDAD ENTRE LOS HIJOS Y EL RESPETO A LA VIDA FAMILIAR Y PERSONAL}

Desde estos planteamientos conviene detenerse en el examen de constitucionalidad realizado por la Cour constitutionnelle sobre la actividad del legislador operada con reforma del Código civil mediante la ley de 1 de julio de $2006^{22}$. Dos son las

20 En virtud de la regulación prevista en el nuevo artículo 55 bis de la LOPJ introducido por la Ley Orgánica 4/2014, complementaria de la Ley de racionalización del sector público y otras medidas de reforma administrativa, la competencia a las Salas de lo civil y de lo penal del Tribunal Supremo tendrán competencia para conocer y tramitar las causas civiles y penales presentadas frente los miembros de la Familia Real, entre los que se incluye al «Rey o Reina que hubiere abdicado y su consorte». Para una visión crítica de este estatuto singular, M. PRESNO LINERA, «Inviolabilidad, inmunidad y aforamiento, ¿garantías o privilegios?», publicado en Agenda pública el 29/06/2014, documento disponible en http://www.eldiario.es/agendapublica/nueva-politica/Prerrogativas-privilegios_0_276122824.html (última consulta el 23/06/2016); Comparte la opción del legislador en este sentido, A. Torres Del Moral, «En torno a la abdicación de la Corona», op. cit., pp. 34 y 35.

21 Vid. al respecto, en la doctrina española entre otros los estudios de L. Portero García, «La responsabilidad del Jefe del Estado», Revista General del Derecho 1982, n. ${ }^{\circ} 448-449$, pp. 4 y ss.; J.M. Porras Ramirez, Principio democrático y función regia en la Constitución normativa Tecnos, Madrid, 1995, en especial pp. 175 y ss. P. Biglino CAmpos, «La inviolabilidad de la persona del Rey y el refrendo de sus actos», Jornadas de Derecho Parlamentario, 2001, Madrid, pp. 244 y 245, B. Oliver León, Monarquía y Estado constitucional, Tecnos, Madrid, 2002; J.F. MERINO MERCHÁN, «Fuero judicial aplicable a la filiación extramatrimonial y a los actos testamentarios del Rey», Revista de Derecho Político, n. ${ }^{\circ} 71-72,2008$, pp. 380 a 382.

22 Esta ley supuso una importante reforma del Código civil respecto del derecho de filiación y sus efectos, siendo modificada meses después por la ley de 27 de diciembre de 2006. Según recuerda la Cour Constitutionnelle en el fundamento jurídico B.3.2 de la sentencia 18/2016, el articulo 7 de la Ley 1 julio de 
cuestiones prejudiciales planteadas por el órgano judicial en virtud del artículo 162 $\mathrm{CB}$, que originan el pronunciamiento constitucional ${ }^{23}$. En primer lugar, se cuestiona la constitucionalidad de la determinación del plazo de un año para ejercitar la acción de impugnación de la filiación de personas mayores de veintidós años cuando, una vez adquirida la posesión de estado, tengan conocimiento de que la verdad biológica y la realidad socio-afectiva no se corresponden (art. 318.2 Cc). En segundo lugar, se plantea la constitucionalidad de la determinación de la posesión de estado como causa de inadmisión de las demandas de filiación (art. 318.1 Cc), En ambos casos, la Cour se utiliza como parámetro de control de constitucionalidad el artículo 22 de la Constitución belga interpretado de conformidad con el artículo 8 $\mathrm{CEDH}$ relativos al respeto a la vida privada y familiar y, por su conexión con la segunda cuestión planteada, los artículos 10 y 12 CB y el artículo 14 CEDH relativos los derechos de igualdad de todas las personas ante la ley y no discriminación.

El análisis de la Cour parte del respeto a la vida privada y familiar como objetivo esencial en esta materia y recuerda, de acuerdo con la jurisprudencia del TEDH que las acciones de filiación, sean de reclamación o de impugnación quedan amparadas por el artículo 8 del CEDH, por cuanto se dirigen sobre aspectos esenciales de la identidad personal ${ }^{24}$. En esta materia rige una concepción amplia del bien protegido «vida familiar», adoptada por el TEDH que viene determinada por la existencia de relaciones familiares fácticas o de derecho entre individuos $^{25}$. En el marco de esta concepción amplia de vida familiar y, atendiendo al margen de apreciación de cada Estado ${ }^{26}$, la jurisdicción constitucional recuerda

2006 establece la posesión de estado como causa de inadmisión de las demandas de contestación de la presunción de paternidad, con el fin de «proteger en la medida de lo possible la unidad familial del hijo manteniendo, por un lado, la possesión de estado que corresponda a un hijo considerado por todos como hijo de sus padres incluso cuando ésto no se corresponda con la filiación biologica, y por otro, estableciendo un plazo pr ejercitar la acción de filiación (Doc. parl., Chambre, 2004-2005, DOC 51-0597/026, p. 6, et DOC 510597/032, p. 31)» (traducción propia).

23 Sobre la cuestión prejudicial y otros procedimientos de control de constitucionalidad ante la Cour Constitutionnelle belga, vid, entre otros, A. ALEN, «Contrôle de constitutionnalité des lois et d'autres actes après leur adoption», Fédéralisme Régionalisme, n. ${ }^{\circ} 1$. Premiers scrutins et contrôle de constitutionnalité en RDC : la mise en œuvre d'une constitution «régionaliste», volume 7, 2007, http://popups.ulg.ac.be/13743864/index.php? id=532. (consultado el 14/06/2016).

$24 \mathrm{Al}$ respecto vid. los fundamentos jurídicos B.5.2 y 3 de la sentencia 18/2016. Sobre este punto son recordadas las SSTEDH de 28 de noviembre de 1984, Rasmussen c. Danemark, párrefo 33; de 24 noviembre de 2005, Shofman c. Russie, párrafo 30; de 12 de enero de 2006, Mizzi c. Malte, párrafo 102; de 16 de junio de 2011, Pascaud c. France, párrafos 48-49; de 21 de junio de 2011, Kruskovic c. Croatie, párrafo 20 ; de 22 marzo de 2012, Ahrens c. Allemagne, párrafo 60; de 12 de febrero de 2013, Krisztissn Barnabsss Tóth c. Hongrie, párrafo 28, entre otras.

25 La Cour constitutionnelle cita la STEDH de 27 octubre de 1994, asunto Kroon contra Países Bajos párrafo 31. Sobre esta concepción también pueden consultarse entre otras las SSTEDH de 18 de diciembre de 1986, asunto Johnston c. Irlanda, párrafo 56; la STEDH de 26 de mayo de 1994, asunto Keegan c. Irlanda, párrafo 44; STEDH de 27 de octubre de 1994, asunto Kroon y otros c. Países Bajos, parágrafo 30 o en la STEDH de 13 de diciembre de 2007, asunto Emonet y otros c. Suiza, párrafo 36.

26 Sobre la aplicación de la doctrina del margen de apreciación en estos supuestos y las obligaciones que en todo caso deben salvaguardarse en los supuestos de investigación de la filiación vid. el asunto Mikuliç 
que el legislador nacional podrá establecer medidas dirigidas a garantizar la efectividad del derecho reconocido en el artículo 22.1 de la Constitución belga. Pero se trata de una facultad legislativa limitada, en la medida en que debe reunir los requisitos de precisión, interés social y proporcionalidad.

Esto es, en la configuración del derecho a la vida privada constitucionalmente protegida, el legislador debe encontrar un justo equilibrio entre los derechos e intereses concurrentes, tanto respecto de aquellos que entran en conflicto entre los individuos y el conjunto de la sociedad, como entre los derechos de las personas directamente afectadas por la medida ${ }^{27}$. Desde este presupuesto, será valorada la constitucionalidad de la limitación absoluta impuesta en el Código civil para interponer acciones de filiación en las condiciones descritas en el apartado primero del artículo $318 \mathrm{Cc}$, esto es, la introducción de la posesión de estado como causa de inadmisión de la acción de filiación (segunda cuestión prejudicial).

III.1. En el análisis de esta cuestión, la Cour constitutionnelle mantiene el criterio sostenido en anteriores ocasiones en las que examina la constitucionalidad del mismo precepto. Así, en la sentencia 147/2013, de 7 de noviembre, la actividad del legislador se estima contraria al artículo 22 de la Constitución conforme al marco de interpretación establecido en el artículo $8 \mathrm{CEDH}$ en la medida en que no es proporcionada a los objetivos e intereses legítimos que deben ser protegidos en estos procesos. Y es que, la paz de las familias y la seguridad jurídica de los vínculos familiares por un lado, y el interés del hijo, por otro lado, constituyen los fines legítimos que persigue una medida que permite al legislador establecer límites para impugnar la presunción de la filiación ${ }^{28}$. La protección del interés del hijo se impone como un fin primordial que orienta la regulación belga y respalda la decisión del legislador de, ante la imposibilidad de lograr un equilibrio entre realidad socio-afectiva y realidad biológica, establecer una preferencia a favor de la realidad afectiva, frente a la biológica, bajo la forma de posesión de estado ${ }^{29}$.

c. Croacia, de 7 de febrero de 2002. Para un análisis de esta jurisprudencia vid. M. Presno Linera, Derecho europeo de familia, Cuadernos Aranzadi del Tribunal Constitucional n. ${ }^{\circ}$ 22, Editorial Aranzadi, Pamplona. 2008, pp. 39-41.

27 En palabras de la Cour, «il ne suffit pas que le législateur ménage un équilibre entre les intérêts concurrents de l'individu et de la société dans son ensemble, mais il doit également ménager un équilibre entre les intérêts contradictoires des personnes concernées (CEDH, 6 juillet 2010, Backlund c. Finlande, $\S$ 46), sous peine de prendre une mesure qui ne serait pas proportionnée aux objectifs légitimes poursuivis». (fundamentos jurídico B.5.4).

28 Según recuerda la Cour en su sentencia 147/2013, afirma que «B.17. La paix des familles et la sécurité juridique des liens familiaux, d'une part, et l'intérêt de l'enfant, d'autre part, constituent des buts légitimes dont le législateur peut tenir compte pour empêcher que la contestation de la présomption de paternité puisse être exercée sans limitation. A cet égard, il est pertinent de ne pas laisser prévaloir a priori la réalité biologique sur la réalité socio-affective de la paternité» (fundamento jurídico B.7.2).

29 Se trata, según ha sido afirmado, de una institución fundamental construida en interés del hijo y que constituye una base constante de la construcción del derecho de filiación belga. Para una visión general de los motivos de la reforma del Código civil belga en 2006, N. Gallus, «Filiation paternelle dans le mariage: le droit de contestation du mari et l'intérêt de l'enfant selon la Cour constitutionnelle», texto disponible en http://www.justice-en-ligne.be/article271.html consultado el 23/06/2016. 
De acuerdo con esto, el legislador impondrá restricciones a las posibilidades de reclamar o impugnar la filiación con el fin de garantizar el vínculo familiar en la medida en que es origen inmediato de derechos y obligaciones paterno-filiares y, de modo destacado, la obligación de prestar alimentos o los derechos sucesorios. En particular, limita las personas legitimadas para iniciar este tipo de acciones civiles y establece la posesión de estado como causa de inadmisión general que impide reclamar la filiación en todos los supuestos y para todos los titulares de la acción. Sin embargo, estas normas civiles que imponen restricciones al ejercicio de la acción de impugnación de la filiación son cuestionadas desde su compatibilidad con el texto constitucional.

En efecto, como en ocasiones anteriores ${ }^{30}$, en el caso analizado, la Cour constitutionnelle estima que una medida legislativa que prive de modo absoluto a los hijos de la facultad de impugnar la presunción de la filiación debe ser considerada inconstitucional por resultar desproporcionada a los fines e intereses de todas las partes implicadas, en particular a los de los hijos. Y es que, convertir la posesión de estado en una causa de inadmisión absoluta de las acciones de filiación sobre la base de una total prevalencia de la realidad socio-afectiva a la verdad biológica priva al hijo de su facultad para impugnar la presunción de la filiación. Así debe ser considerado, incluso, como en el caso objeto de este análisis, en la hipótesis de que el hijo haya dejado consolidar la posesión de estado teniendo conocimiento de la realidad biológica. Pues, según afirma la Cour, esa actitud puede obedecer a motivos diversos y no necesariamente a una «manifestación libre y clara de la voluntad irreversible del hijo de que prevalezca su filiación legal sobre su filiación biológica» ${ }^{31}$. En definitiva, el examen de constitucionalidad realizado sobre esta cuestión conduce a la Cour a confirmar su doctrina anterior y declarar la inconstitucionalidad de la actuación del legislador en este punto.

III.2. Por otra parte, respecto al segundo bloque de la argumentación de esta decisión, esto es, el examen de la constitucionalidad de la determinación del plazo de un año para ejercitar la acción de impugnación de la filiación para personas mayores de veintidós años (primera cuestión prejudicial), la Cour parte de nuevo de la doctrina del margen de apreciación de los Estados. Y es que, ante la inexistencia de un consenso unánime en esta materia sobre el interés en juego o el modo en que ese interés debe ser protegido ${ }^{32}$, la determinación de un plazo para iniciar una acción de filiación puede ser justificada para garantizar seguridad jurídica y el carácter definitivo de las relaciones familiares. En todo caso, el artí-

30 Entre otras, las sentencias 20/2011, de 3 de febrero, 122/2011, de 7 de julio; 29/2013, de 7 de marzo; 105/2013, de 9 de julio. Una crítica a la sentencia de 20/2011, de 3 de febrero de la Cour Constitutionnelle recaída sobre esta cuestión, puede consultarse N. GALLUS, «Filiation paternelle dans le mariage: le droit de contestation du mari et l'intérêt de l'enfant selon la Cour constitutionnelle», op. cit.

31 Vid. al respecto FJ B.7.4 de la sentencia 18/2016, de 3 de febrero.

32 Vid. al respecto FJ B.10.2 de la sentencia 18/2016, de 3 de febrero, donde se recuerdan las SSTEDH de 22 de marzo de 2012, Ahrens c. Alemania, párrafo 68 ; 15 de enero de 2013, Laakso c. Finlandia, párrafo 41. 
culo 8 del CEDH impone al legislador que la medida logre un equilibrio entre los intereses individuales y los intereses generales, además de los intereses particulares concurrentes en juego ${ }^{33}$. Desde esta premisa, la Cour mantiene una argumentación construida sobre la jurisprudencia del TEDH.

De nuevo, como sucediera en el análisis de apartado primero del artículo 318 Cc con el artículo 8 del CEDH y el artículo 22 del texto constitucional, se podría invocar la paz familiar y la seguridad jurídica de los vínculos familiares, por un lado, y el interés del hijo, por otro lado, como los fines legítimos que permiten al legislador establecer un plazo límite para impugnar la presunción de la filiación. Sin embargo, retomando su doctrina anterior expuesta en la sentencia 96/2011, de 31 de mayo, la Cour confirma el trato discriminatorio al que se somete a aquellas personas que se encuentran en el supuesto de hecho previsto por la norma civil, esto es, mayores de veintidós años o aquellas respecto de las cuales haya trascurrido un año desde que conocieron que realidad biológica y la realidad socio-afectiva son distintas ${ }^{34}$. A juicio de esta jurisdicción constitucional, en estos supuestos, el legislador belga vulnera el principio de igualdad y no discriminación entre los hijos garantizado constitucionalmente (artículos 10, 11, 22 CB) y, por su conexión, el respeto a la igualdad en el ámbito familiar y privada del individuo garantizados en el CEDH (artículos 8 y $14 \mathrm{CEDH})^{35}$. Y es que, la eventual paz familiar no puede justificar la quiebra de la igualdad en el acceso a la jurisdicción que implica la existencia de un plazo para ejercitar la acción de filiación a determinados sujetos, y por ello, impide a todas las personas afectadas un pronunciamiento judicial sobre los hechos y los intereses que les conciernen.

No obstante, conviene considerar que este pronunciamiento presenta como particularidad la existencia de la posesión de estado adquirida por la hija demandante. Al respecto, según advierte la Cour constitutionnelle, al margen de la edad en que se conozca que realidad biológica y realidad afectiva difieren, esto es, incluso si hay vínculos familiares establecidos por la posesión de estado, los procedimientos de filiación entran dentro de la vida privada del individuo y, con ello, el derecho de toda persona a la determinación de la filiación debe prevalecer al interés de la paz familiar y la seguridad jurídica de los lazos familiares ${ }^{36}$. La jurisprudencia del TEDH es, en este punto, pilar esencial de la argumentación de la Cour constitutionnelle. Y es que, en efecto, cuando entra en juego el derecho a conocer la propia identidad es necesario ponderar todos los intereses concurrentes y considerar además, que el interés por conocer los ascendientes no disminuye con la edad,

33 FJ B.10.3 de la sentencia 18/2016, de 3 de febrero, y por remisión las STEDH de 20 diciembre de 2007, Phinikaridou c. Chipre, párrafos 51 a 53.

34 FJ B.11.1 de la sentencia 18/2016, de 3 de febrero.

35 FJ B.11.2 de la sentencia 18/2016, de 3 de febrero.

36 FJ B.15 de la sentencia 18/2016, de 3 de febrero. 
más bien al contrario ${ }^{37}$. Además, según se deja constancia en la sentencia constitucional, la norma civil objeto de control de constitucionalidad, además de ser extraña en el derecho comparado europeo, produce una «injerencia desproporcionada» sobre la vida privada del hijo. El corto plazo de tiempo fijado en la norma puede privar al hijo/a de ejercitar su derecho de acceso a la jurisdicción y obtener por tanto, una decisión judicial fundada sobre los hechos y los intereses en conflicto ${ }^{38}$ que, en definitiva, determina una posición de desigualdad con respecto a los derechos y obligaciones que pudieran derivarse del reconocimiento judicial de la filiación.

En suma, los derechos a la igualdad y a la tutela judicial efectiva en su vertiente de acceso a la jurisdicción respaldan la interpretación flexible realizada en esta decisión de la Cour que declara inconstitucional la determinación de un plazo para ejercitar las acciones de filiación en los términos previstos por el legislador belga. Se trata a nuestro juicio de una decisión congruente con el respeto de los derechos e intereses a los que sirven las acciones de filiación y, en particular, el derecho a conocer la propia identidad u origen biológico, derecho que «guarda intima conexión con la dignidad humana» ${ }^{39}$. Desde una perspectiva constitucional, parece pues conveniente flexibilizar las condiciones o limites que restringen las posibilidades para ejercitar una acción vinculada con la identidad personal y los derechos conectados con el respeto a la vida privada, derechos que, en caso de conflicto, deben ser considerados preferentes al mantenimiento de la paz familiar o la seguridad del vínculo familiar. Así pues, una flexibilización del procedimiento en este punto nos parece legitimada por los derechos y fines constitucionales a los que sirve los procedimientos de esta naturaleza.

\section{CONCLUSIONES}

El estudio de esta decisión de la Cour constitutionnelle acerca de las cuestiones prejudiciales planteadas por la jurisdicción ordinaria merece una valoración final. En primer lugar, conviene recordar que el interés del análisis dogmático de esta decisión se proyecta sobre una de las particularidades que presenta desde su origen judicial. La singularidad del sujeto frente al que se dirigen las acciones de filiaciones, el monarca belga abdicado. Esta circunstancia nos permite examinar aspectos esenciales que definen la posición constitucional del monarca como titu-

37 FJ B.14.1 y 2 de la sentencia 18/2016, de 3 de febrero, donde la jurisdicción belga recuerda las SSTEDH, 13 julio de 2006, Jäggi c. Suiza, párrafos 37 y 40; 3 de abril de 2014, Konstantinidis c. Grecia, párrafo 47; 16 juin 2011, Pascaud c. Francia, párrafo 65).

38 FJ B.16 de la sentencia 18/2016, de 3 de febrero.

39 En palabras de nuestro TC la investigación de la filiación «guarda íntima conexión con la dignidad de la persona (art. 10.1 CE), tanto desde la perspectiva del derecho del hijo a conocer su identidad como desde la configuración de la paternidad como una proyección de la persona» (STC 138/2005, FJ 4). 
lar de la jefatura del Estado. Como también examinar su estatuto jurídico, en especial, las prerrogativas de la inviolabilidad regia y el fuero jurisdiccional, entre las que se aprecian diferencias con respecto a la regulación española que, a nuestro juicio, deben ser valoradas positivamente en la medida en que compatibilizan mejor con los principios y valores del Estado constitucional de Derecho. Pues, por su vinculación jurídica con la institución de la jefatura del Estado, las prerrogativas regias merecen ser limitadas temporal y materialmente a los actos públicos que realiza su titular. Esta comprensión reducida o limitada asumida por el constitucionalismo belga se muestra más congruente con el respeto al principio de igualdad en cuanto eje vertebrador del sistema democrático.

Por otra parte, respecto al contenido de la sentencia constitucional analizada, apreciamos una línea argumental construida sobre una consolidada doctrina del TEDH sobre la noción de «vida familiar» y, con ello, sobre el derecho de toda persona a esclarecer su filiación. De este modo, el pronunciamiento constitucional se muestra coherente con los derechos y fines constitucionales a los que sirven las acciones de filiación. $\mathrm{Y}$ es que, los procesos de filiación permiten materializar el derecho de toda persona a esclarecer o conocer el propio origen biológico y se ponen al servicio del principio de igualdad y no discriminación como mecanismo para lograr su efectividad.

En la medida en que estamos ante derechos directamente conectados con la dignidad de la persona, una interpretación amplia o flexible de las normas procesales y civiles en los procesos de filiación resulta a nuestro juicio legítima. El objetivo de una interpretación flexible de las normas procesales no es otro que garantizar el pleno ejercicio del derecho de acceso de todos en condiciones de igualdad a la jurisdicción. Las consecuencias prácticas de esta interpretación para las relaciones paterno-filiares son claras. Pues, como ha sido recordado, los efectos de los procesos de filiación tienen una indudable proyección en la esfera patrimonial o material y no sólo en el ámbito socio-afectivo de los hijos. Las obligaciones de prestar alimentos o los derechos sucesorios son expresión clara de unos intereses patrimoniales de los hijos que han de ser efectivamente amparados por el sistema jurídico. Por eso, entendemos que la comprensión finalista mantenida por la Cour Constitutionnelle debe ser valorada en un sentido positivo, en la medida en que flexibiliza la rigidez de las normas jurídicas en aras de garantizar los derechos de la esfera privada y las posiciones de igualdad entre los hijos.

$$
* * *
$$

\section{TITLE: Affiliation and abdication actions in belgian constitutional monarchy}

AвSTRACT: This paper analyzes the decision by the Belgian Cour constitutionnelle n. ${ }^{\circ}$ 18/2016, 3 February. In this decision, the Court examines the constitutionality of 318 paragraphs first and second, of the Belgian Civil Code, due to the presentation of two referred questions by the Court of First Instance francophone in Brussels. The analysis of this decision in the context of the processes of filiation, lies at the heart of the legal reflection the rights to private and family life, the development of children and the guarantee the 
preferential nature of the interest of the child in all that it is concerned, and by their connection also the right to equality and non-discrimination among children. The constitutional judgment will be constructed over the jurisprudence of the ECHR regarding the content and scope of rights to private and family life. Moreover and regardless from the media and social impact of the material matter, the facts that substantiate the cause of filiation project this legal analysis on the status of the monarch as head of the Head of State and on the consequences of the abdication in the crown.

RESUMEN: El presente trabajo analiza la decisión de la Cour constitutionnelle belga 18/2016, de 3 de febrero, mediante la cual se examina la constitucionalidad del artículo 318 en sus apartados primero $y$ segundo del Código civil belga, a raíz de la presentación de dos cuestiones prejudiciales por el tribunal de primera instancia francófono de Bruselas. El estudio de esta decisión sobre la constitucionalidad la actuación del legislador en el ámbito de los procesos de filiación, evidencia la relevancia constitucional de una causa que sitúa en el centro de la reflexión jurídica los derechos a la vida privada y familiar y al desarrollo del niño $y$ la garantía del carácter preferente del interés del bijo en todo aquello que le concierna, y por su conexión, también el derecho de igualdad y no discriminación entre los hijos. El juicio de constitucionalidad será construido sobre la jurisprudencia del TEDH relativa al contenido y alcance de los derechos a la vida privada $y$ familiar. Junto a ello, y al margen de la repercusión mediática y social del asunto material, la singularidad del sujeto frente que dirigen las acciones filiación que origina el pronunciamiento constitucional, proyectan este análisis jurídico sobre el estatuto jurídico del monarca y sobre las consecuencias de la abdicación como titular de la Jefatura del Estado.

KEY WORDS: Filiation, crown, abdication, equality, right to private and family life.

PALABRAS Clave: Filiación, corona, abdicación, igualdad, vida privada y familiar.

FECHA DE RECEPCIÓN: 07.07.2016

FECHA DE ACEPTACIÓN: 27.07.2016 